\title{
Taobao practices, everyday life and emerging hybrid rurality in contemporary China
}

Abstract: Over the past decade, e-commerce has spread throughout China, providing an economic advancement opportunity for those in the lower classes of society. Villages who specialise in e-commerce, such as the Taobao villages, are booming. Taobao villages constitute an exciting phenomenon that has changed both the pattern of the rural economy, as well as the social foundation of rural daily life. This paper explores how everyday life in rural China has changed in response to the development of the network economy. Using Junpu village in Guangdong Province as a case study, our findings suggest that the development of e-commerce and network technology has changed the common values held towards rural life, the affection felt for the village, and the pace of life of local people. This development has also led to social separation in rural China. However, the intrusion of this new force of network economy has been resisted by local cultural structures such as family, clans, religion, and gender dynamics, leading to an unprecedented hybrid rurality. While network development has brought about the influence of modernity, the Chaoshan tradition of Junpu village has persisted and continued to be a part of life in this new stage of social life. The social milieu in rural China has been reconstructed and blends the alienation brought on by the operation of a network economy with the resistance felt from the practice of local cultural traditions.

Keywords: hybrid rurality; Taobao; everyday life; local culture; China 


\section{Introduction}

Rural development in Western countries in the past few decades has witnessed a process of de-agricultralization and post-productivism, since rural villages gradually made a transition from agricultural economy to a more diverse array of economic activities, including handicraft industry, retailing, and tourism (Marsden et al., 1993; Hoggart and Paniagua, 2001; Roche, 2003). This dramatic transformation has led a number of scholars to call for a post-rural perspective in understanding rural development (Murdoch and Pratt, 1993; Hopkins, 1998; Halfacree, 2006). This is particularly necessary when information and communication technology has become a driving force in transforming rural economies and societies since the 1980s, connecting rural settlements more inextricably with networks of the global economy (Nelson, 2001; Cloke, 2006). This post-rural perspective emphasizes the mixture of hybridity, diversity, and heterogeneity in villages and argues that rural progression does not fully depend on a single sector, but is rather embedded into the intertwined and mutually constitutive production of rural space through material and discursive phenomena, processes and practices (Marsden, 1998; Woods, 2011; Heley and Jones, 2012).

Since the economic reform began in 1978 in China, rapid industrialization and urbanization have profoundly reshaped the trajectory of rural development in the country as more and more villages have experienced a similar process of economic restructuring and cultural diversification to their Western counterparts (Long et al., 2016; Long and Liu, 2015; Long and Woods, 2011; Xu and Tan, 2002). Information technology has deeply affected social structures and everyday life in numerous villages across the world (Salemink et al., 2015; Kilpeläinen and Seppänen, 2014; Michailidis et al., 2011). China is no exception to this trend. According to the latest report by 
China Internet Network Information Centre, internet-based information technology has become a predominant factor in the shaping of internal social ties and the reconfiguration of daily life in numerous Chinese villages. ${ }^{1}$ Many scholars have also noted that information technology and internet-based economy have accelerated the process of de-agriculturalization and changed both the pattern of the rural economy and the routines of rural social life (Soriano, 2007; Zhao, 2008; Qiang, 2009; Oreglia, 2014).

China's Taobao village is a prime example of this phenomenon. Within the context of China's emerging e-commerce industry, some villages utilize a digital commercial platform provided by Taobao, the biggest e-commerce corporation in China and in the world, to become new centres of internet-based retail economy. Initiated by Alibaba Group Holding Limited, Taobao's business model involves a long industrial chain, and stimulates the development of various workshops that specialize in activities such as processing, manufacturing and logistics. The aggregation of these workshops in rural areas has led to the development of so-called 'Taobao villages', which has contributed to the rapid restructuring of the rural economy. In these villages, Taobao practices ${ }^{2}$ have blurred the line between life and work, and become an important component of villagers' daily lives. The embeddedness of the modern network economy in China's rural space has sparked a complex dialogue between modernity and rurality, and given rise to an unprecedented type of hybrid rurality.

\footnotetext{
${ }^{1}$ China Internet Network Information Centre (2015), "Research Report on the Rural Internet Development of 2014", available online at: http://www.cnnic.cn/hlwfzyj/hlwxzbg/201506/P020150623466458430466.pdf, last accessed 29 April 2016.

${ }^{2}$ In this study, 'Taobao practices' refer to various online and offline practices that are undertaken by rural villages in relation to the business of Taobao. In particular, it indicates the impacts that are rendered by the clustering of Taobao businesses upon the daily life of rural residents. These include changes to common values that are held in terms of rural life, the affection felt towards the village, and the pace of rural life. Although Taobao is an online market, there are offline businesses that are providers of various goods and services and are located in rural villages, such as Junpu village, the site of this case study.
} 
This paper explores how everyday life in rural China changes in response to the influx of e-commerce activities. In this process of economic restructuring, reconstruction of rural subjectivity and values reflect the rural area's response to the transformation of the economy and society. This has occurred through the villagers' reselection of their life style and means of livelihood, as well as changes in the rural family structure, and the reconstruction of gender roles and social relations in rural areas (Qian et al., 2012; Fang and Liu, 2014; Liu and Liu, 2016; Judd, 2009; Ling et al., 2013; Huhe, 2015). Additionally, traditional rural cultures have power that cannot be overlooked in the rural areas of China that are currently transforming from an agricultural society to a modern society. Deep-rooted rural beliefs, familial relations and geo-relations continue to resist the forces of modernity in many areas (Chung, 2013). We examine how rurality, as a form of everyday life, was reconstructed under the network economy represented by the expansion of Taobao. An analysis of rural values, rural feelings, the pace of rural life, and changes in the rural space of Taobao villages assists with the interpretation of how the relationship between the vernacular traditions of rural people and modernity has been represented in the development of e-commerce, and creates a dialogue about studies of rurality in the post-rural era.

With the hybrid reconstruction of rural areas through the process of globalization (Murdoch, 2003, 2006; Woods, 2007; Woods, 2009) and the inherent openness of the post-rural era (Halfacree, 2009), rurality has been viewed as a complex interwoven state in which various forces continuously unify and separate (Cloke, 2006). In this study, the concept of hybridity is introduced, and is combined with Lefebvre's theory of everyday life to explain the reconstruction of rurality and its relationship with modernity. Lefebvre argued that alienation under modernity 
engulfs all of human life and portrayed the 'everyday' as a practice that is banal, repetitive and lacking in creativity (Lefebvre, 1983). He and de Certeau (1988) independently noted that the public, in fact, experiences tremendous de-alienation and there is much creative potential integrated into their daily lives. Lefebvre's theory of everyday life in modernity is still relevant in the explanation of the relationship between modernity and rural traditions.

Integrating the perspectives of rural hybridity and the theory of alienation in order to interpret how the Taobao village operates under a network economy can help illustrate this unique form of rurality. In research on rurality, the understanding of hybridity in the 'post-rural' context emphasizes a type of subjective practice that adopts a wider perspective. By treating modernity and rurality as interactive subjects, we explain the complexity of this hybridity from the perspective of a new practical relationship. In discussing how modernity collides with China's rural traditions, this paper restores a multidimensional rural cultural scene that rurality research is rarely able to address. This is achieved through an explanation of the daily negotiations of alienation and de-alienation that occur in this context.

\section{Research methods}

Junpu village in Xichang Township, Jieyang City, in eastern Guangdong Province of China has 490 families who live locally (Fig. 1). After China's economic reforms, the economy of Junpu village gradually transformed from agricultural industry to the food industry. At the peak of Junpu's development, $80 \%$ of the village population was involved in the production of biscuits, jellies, and chocolates. Despite previously being a reputable site of production across the region, the food industry gradually declined because of a redundant business philosophy and 
lower-quality products. ${ }^{3}$ In light of this diminishing industry, from 2012 onwards, young people who had returned home to the rural areas after living in cities began using the former food production warehouses to open Taobao shops. In 2014, 360 households in the village were running 3,880 Taobao shops, which in turn influenced surrounding towns and villages to set up nearly 10,000 Taobao shops. ${ }^{4}$ In 2013, Junpu village became one of the top 20 Taobao villages, and therefore represents a typical case of the drastic change occurring in China's internet-based economy. ${ }^{5}$

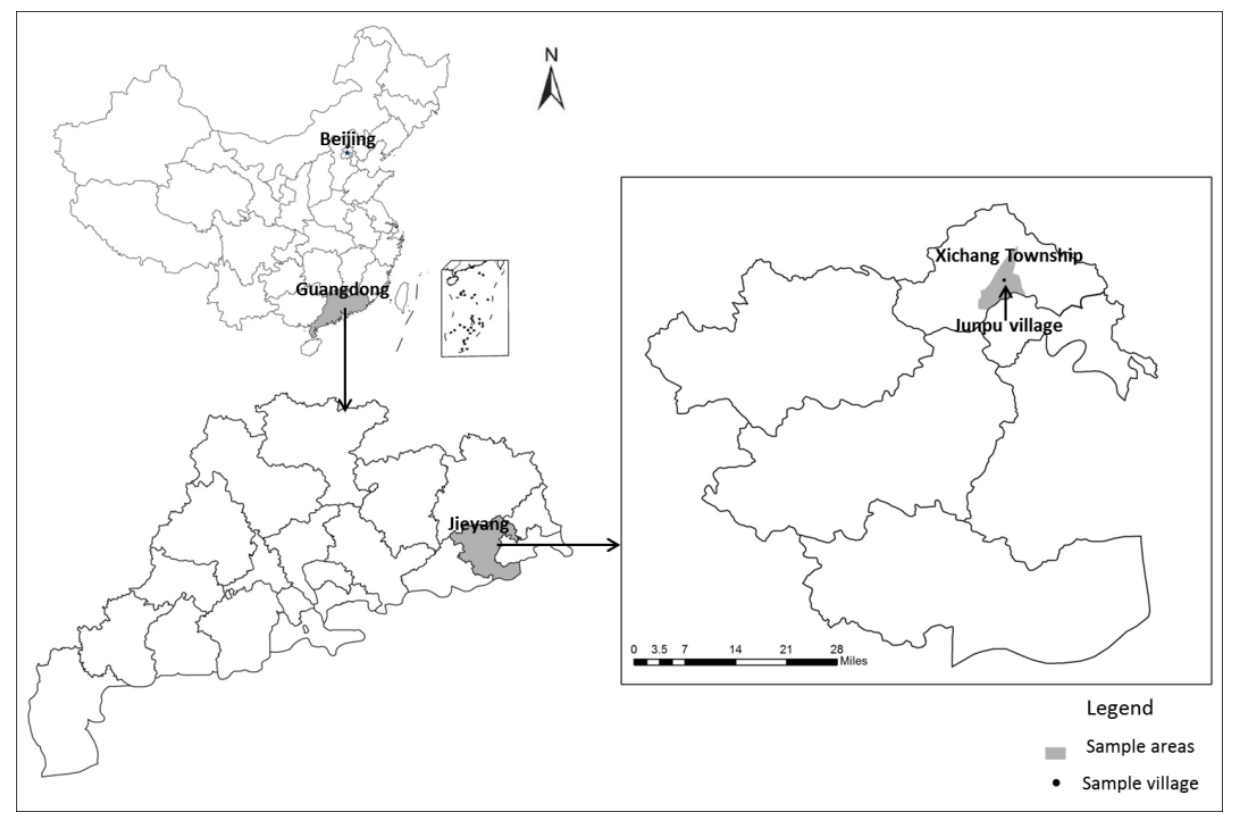

Fig. 1. Location of Junpu village.

Major research methods used in this study are semi-structured in-depth interviews, together with participatory observations. The temporal pattern of Taobao transactions meant that the interviews and investigation were conducted from July to December 2014 and from February to

\footnotetext{
3 "Introduction of Taobao village in Jieyang", Internal report of Jieyang Municipal Government Office, released on 10 August 2015.

4 "Investigation of e-commerce trade in Jiedong district and speaking at the International Conference on Electronic Commerce Development in Guangdong Province", Internal report of Jieyang Municipal Government Office, released on 15 August 2015.

5 AliResearch (2014), "Chinese Taobao village research report", available online at: http://i.aliresearch.com/img/20141223/20141223100803.pdf, last accessed 18 April 2015.
} 
March 2015. The investigation covered both usual transaction periods, and those surrounding special occasions (e.g. November 11, December 12, and Chinese New Year). ${ }^{6}$ A total of 28 in-depth interviews were conducted with three types of Junpu villagers: large Taobao traders, ordinary Taobao shop owners, and those who were not involved in Taobao business operations at all (Table 1). The respondents ranged in age from 20-75 years old and had relatively low levels of education. The interviews began with well-known Taobao shop owners in the village. Thereafter, snowball sampling and in-house visits were combined in order to conduct more interviews.

The goal of the interviews was to investigate how online economic practice affects the traditional rural area in certain aspects of everyday life such as gender relations, family structures, and beliefs held by community members, as well as the reflected mutual relationship between modernity and rurality of the area. Specifically, the interviews centred on the changes in or continuance of aspects such as values, affective identification, social interactions, family relations, daily labour divisions, pace of life, festivals and celebrations, and everyday life space of villagers. In addition to the first-hand information gathered through the interviews, second-hand data was collected from government's official documents, relevant Weibo (China's equivalent of Twitter) content, news media reports, etc. The media reports cover the period from July 2013 to April 2015, and include text-based and video-based news.

\section{Table 1}

Basic characteristics of the 28 interviewees in Junpu village.

\begin{tabular}{ccccc}
\hline ID & Sex & Age & $\begin{array}{c}\text { Do you or your family members } \\
\text { run the Taobao shop? }\end{array}$ & $\begin{array}{c}\text { Size of the } \\
\text { Taobao shop }\end{array}$ \\
\hline 1 & $\mathrm{M}$ & $35-39$ & $\mathrm{~N}$ & --- \\
\hline
\end{tabular}

${ }^{6}$ November 11 and December 12 are Internet shopping festivals launched by Alibaba, and the Spring Festival is the grandest traditional festival in Chinese folk culture, when villages in Chaoshan hold large annual ceremonial activities in order to honour their ancestors. 


\begin{tabular}{|c|c|c|c|c|}
\hline 2 & $\mathrm{M}$ & $55-59$ & $\mathrm{Y}$ & Ordinary \\
\hline 3 & M & $40-44$ & $\mathrm{Y}$ & Ordinary \\
\hline 4 & $\mathrm{~F}$ & $35-39$ & $\mathrm{Y}$ & Ordinary \\
\hline 5 & M & $60-64$ & $\mathrm{~N}$ & --- \\
\hline 6 & $\mathrm{~F}$ & $60-64$ & $\mathrm{Y}$ & Large \\
\hline 7 & M & $55-59$ & $\mathrm{~N}$ & --- \\
\hline 8 & M & $20-24$ & $\mathrm{Y}$ & Ordinary \\
\hline 9 & $\mathrm{~F}$ & $20-24$ & $\mathrm{Y}$ & Ordinary \\
\hline 10 & $\mathrm{~F}$ & $50-54$ & $\mathrm{Y}$ & Large \\
\hline 11 & $\mathrm{~F}$ & $40-44$ & $\mathrm{Y}$ & Ordinary \\
\hline 12 & $\mathrm{~F}$ & $20-24$ & $\mathrm{Y}$ & Ordinary \\
\hline 13 & M & $25-29$ & $\mathrm{Y}$ & Large \\
\hline 14 & M & $50-54$ & $\mathrm{Y}$ & Ordinary \\
\hline 15 & M & $25-29$ & $\mathrm{Y}$ & Ordinary \\
\hline 16 & M & $20-24$ & $\mathrm{Y}$ & Large \\
\hline 17 & M & $25-29$ & $\mathrm{Y}$ & Ordinary \\
\hline 18 & M & $40-44$ & $\mathrm{Y}$ & Ordinary \\
\hline 19 & M & $70-74$ & $\mathrm{Y}$ & Large \\
\hline 20 & $\mathrm{~F}$ & $20-24$ & $\mathrm{~N}$ & -- \\
\hline 21 & $\mathrm{~F}$ & $60-64$ & $\mathrm{~N}$ & --- \\
\hline 22 & M & $70-74$ & $\mathrm{Y}$ & Large \\
\hline 23 & M & $45-49$ & $\mathrm{~N}$ & --- \\
\hline 24 & M & $50-54$ & $\mathrm{Y}$ & Ordinary \\
\hline 25 & M & $50-54$ & $\mathrm{Y}$ & Ordinary \\
\hline 26 & M & $40-44$ & $\mathrm{Y}$ & Ordinary \\
\hline 27 & $\mathrm{~F}$ & $45-49$ & $\mathrm{Y}$ & Ordinary \\
\hline 28 & $\mathrm{~F}$ & $40-44$ & $\mathrm{Y}$ & Ordinary \\
\hline
\end{tabular}

\section{Reconstruction of rural daily life and identity}

\subsection{The identity of rural values}

In Junpu village, the services and business opportunities provided by Taobao are penetrating into practically all aspects of the villagers' everyday life. This new business model has not only generated new and major topics in villagers' daily conversations, but also quietly changed the identity of the village as a rural community and their associated values. The interests covered in villagers' everyday conversations were centred around how to improve their Taobao business operations or how to increase merchandise sales. Examples of these conversations include, 'What 
kind of clothes have sold quickly recently?'; 'What styles of clothing are unpopular?'; and 'How is the shop's business?'.

Despite the presence of Taobao in daily life, there is not concurrent promotion of harmonious community relationships among neighbours in the village. The Taobao village has gradually expanded because of the mutualism of China's traditional acquaintance society. Many Taobao shops were opened with the assistance of relatives or friends. Competition intensified among the villagers as the number of Taobao shops increased. To reap more economic benefits, many villagers adopted the strategy of low-price competition and merchandise mimicking. As a participant in Liu's (2014: 100) study explained, 'everybody is selling clothes; everybody is selling the same style less than a month after a new product comes out'. A female trader in her 50s in our survey further stated that, 'At the beginning, Weilong and Daqian came and got goods from us and sold them on Taobao. Now they are running a good business and selling at a discounted price, at only six yuan a piece'.

In the context of a deeply embedded and influential nature of the network economy, traditional kinship-style mutualism has rapidly shifted. This is due to homogeneous competition between traders, and thus Taobao gradually changed the moral fibre that had previously shaped traditional rural communities. As a villager narrated, 'The interpersonal relationship in the village appears to be not as harmonious as it was before; it was not so contentious back then'. ${ }^{7}$ Junpu village immediately established the E-Commerce Association, in order to avoid taking each other out by vicious competition. Under the leadership of the Association, an agreement was signed that

\footnotetext{
7 “Taobao village: villages changed by the Internet", People's Daily, 09 January 15, available online at: http://www.gd.xinhuanet.com/newscenter/2015-01/09/c_1113941836_2.htm, last accessed 10 September 2015.
} 
ensured each store owner would be able to sell their own specialty products, which would in turn reduce the frequency of poor competitive business practices.

Traditional daily interactions between villagers had therefore evolved into the pursuit of beneficial economic activities. Taobao has not only changed the trust among the villagers within Junpu village, but also directly altered the identity of the villagers as people who value 'integrity'. In aiming for success in their businesses, villagers were seen to be abandoning their credibility. To mitigate this perception, Taobao shop owners created fake images of various products' popularity, with some sellers using 'tactical' deception that involved false transactions, i.e., shipping 'empty packages' (Fig. 2). As a villager described in his Weibo, 'In the areas surrounding the Junpu Taobao village, a half-dozen shops were opened and specialised in selling the "empty package". 8 To have good reviews from their customers, some Taobao shops have used also bribery. As one female respondent in her 20s, who owned an Ordinary Taobao shop, told us, 'If a buyer gives us a negative review, we will go and talk to him. We normally offer to refund the buyer five yuan in exchange for a revised, positive review. This strategy works most of the time'.

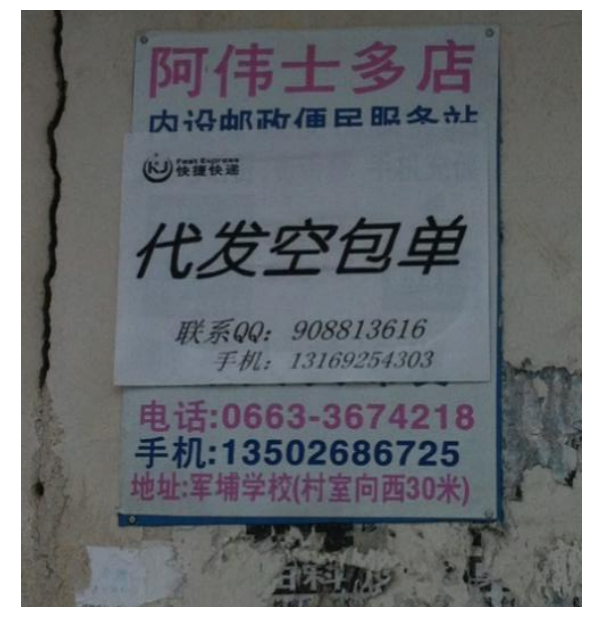

Fig. 2. An advertisement for an 'agent sending empty package lists' posted on the wall by the villagers.

\footnotetext{
${ }^{8}$ Collected from Weibo, available online at: http://weibo.com/p/1005052489042295, last accessed 10 September 2015.
} 
Data source: photographs by the authors.

In metropolitan areas, money has become the only yardstick for measuring value resulting from the development of a modern monetary economy (Simmel, 1978). The network economy uniformly quantified the values of villagers, insofar as villagers' daily interests, life skills, and personal success were all represented through Taobao practices. Traditional rural values were unconsciously modified. Daily interactions and communications have been transformed into tools for realizing one's economic goals. The villagers were rarely grateful for others' assistance in their start-up businesses. In the Chaoshan rural communities, the usually close relationships between people in the same clan underwent a utilitarian reconstruction, in part due to changes stemming from the Taobao economy.

Fei (2008) characterised the basic community of a rural society as the 'expanded family' that 'sustains private morality'. In the context of individuals and business owners pursuing economic self-interest, traditional morality has been converted into a utilitarian interaction mode, altered by the presence of Taobao in this community. Interestingly, Taobao practices initially produced a spirit of selflessness and solidarity in the villagers, but the traditional local value of selflessness and solidarity was quickly pushed out by the Taobao economic laws, which encourage self-centredness in the production process. The modernity represented by Taobao accelerated the erosion of traditional rural society's integrity through the use of the market's competitive forces. This has led to reconfigured rural conventions that contain features of the modern contract.

Studies on traditional rural community values have shown that modernity has elevated the level of societal individuality, reduced interdependence, and undermined mutualism (Burholt et al., 
2013; Ooi et al., 2015; Wen et al., 2009). In some cases, it even destroyed individual or collective identities, but the ever-changing rural reconstruction under various intertwined forces was not singularly positive or negative - instead exhibiting a high degree of multiplicity (Jackson, 1991; Nelson, 2001). In Junpu village, modernity's reconstruction of rural daily values through Taobao practices again precipitated a similar state of hybridity.

\subsection{The emotional identity of the rural community}

The Taobao industrial chain has established a partnership relationship that includes customer service, shipment pick-ups, packing, delivery, and after-sales services. Although these workshop-style Taobao practices have industrialized the family, they have also heralded a return to traditional family relations through the reinforced division of roles. In patriarchal family relations in the Chaoshan area, women often played a subsidiary role. After the economic reform in China, numerous women migrated from the countryside to urban areas to seek work, and gradually shed their domestic-oriented role in the family. However, after the cooperative relations of production implemented under Taobao were embedded into the family structure, traditional gender roles within the family were reproduced against a modern backdrop.

A female Ordinary Taobao shop owner in her 20s explained that,

After graduating from junior high, I went to Shenzhen and stayed there for five or six years. Actually, this business is my brother's wholesale shop. My dad thought my elder brother, as a man, should have his own career. So, he asked my elder brother to come back to the village to start his own business and asked me to come back to help my brother.

Another shop owner in her 20s commented that, 
I'm here to help my brother run a Taobao shop. In the morning, I tend the store; in the afternoon, I do customer service and packing for shipment. I graduated from high school last October and came over to help.

Taobao practices also prompted women's returns to their traditional roles within the home. Heller believes that religion retains strong routine characteristics in contemporary times (Lefebvre, 2008). Chaoshan people fervently believe in ghosts and spirits, and conduct all types of worship activities. In addition to the arrangements made for eight most important festivals, namely the Spring Festival, the Lantern Festival, the Qingming Festival, the Dragon Boat Festival, the Ghost Festival, the Mid-Autumn Festival, the Winter Solstice, and Chinese New Year's Eve, they also hold routine worship activities on the first and fifteenth days of each month in Chinese lunar calendar. Moreover, activities are arranged in order to worship local deities and ancestors. These routines are usually run by the women in the family. Many women in the rural Chaoshan area have deep-rooted family values and religious beliefs that they are fervently committed to. By managing the worship activities in their daily lives, they attained a strong identity of being a 'housewife'. In the interviews, women reported that taking care of their families when they were working as migrant workers in cities was very challenging as there were scheduling conflicts. These women were unhappy with the conflict seen between their social role in the workplace and their family role. As one Ordinary Taobao shop owner in her 40s explained,

A woman certainly should look after her family. The first and fifteenth days of each month in Chinese lunar calendar will take two days, not to mention the days when we honour our ancestors. It adds up to so many days that women cannot work in the factory. Most of the people in the village are generally running a Taobao business now. They do 
not need to always be on the go. When we are at home, we can work early or late, nobody controls us.

Operating family-owned Taobao shops allowed more flexibility in their schedules, many women were able to return to their traditional role as a housewife and regain traditional family ties through daily activities, such as worship activities. In this way, women were able to perform both social and family roles. This shows the mutual reconstruction of family culture as it uniquely pertains to the Chaoshan area within the modern network economy.

In addition to women returning to and identifying with the family, the business opportunities provided by Taobao have recalled young people to rural communities. Depopulation and an ageing population are social problems that many rural areas in China are currently experiencing, and Junpu village is not exempt from facing these issues too (Liu, 2014). Having said this, the network economy enables the elderly and children to regain a complete family life. As a Large Taobao trader in his 70s noted,

If Taobao could not be run at home, family members would have to work as migrant workers in the faraway cities; otherwise, how do you make a living? The family members scatter around, so what's the point? Once the Taobao shop is open, a few hundred orders will satisfy us.

The Taobao economy has attracted many young people choosing to return home in a case of the 'pull factors' overpowering the 'push factors' (Lee, 1966). This means that the emotional factors that drive migration decisions are no less important than the economic ones. Running a Taobao shop has made it possible for young people to live with their families, and this opportunity mitigates the previous decline of the village which forced the young to be away from their homes. 
Nelson's (2001) study on rural reconstruction noted that rural economic development has positive aspects in that it created more job opportunities that were favourable for family reunification and cohesion. In a similar way, the development of network economy in Junpu village has helped young people reintegrate themselves with 'a feeling [of being] at home' and belonging (Easthope, 2004). For the villagers returning home, the concept of 'home' and the 'hometown' are intertwined, and Junpu village has become a symbol of 'home'.

One Ordinary Taobao shop owner in his 50s described how his family 'used to run a Chaoshan specialty tasty food store in Shenzhen, and we came back about three years ago. Our children were also migrant workers and also returned about three years ago. It's better being at home than being far away from home, being surrounded by acquaintances'.

Young people's emotional identification with rural communities partially originated from the transformation of their social identities. Compared with the restrictions associated with their work and daily lives as migrant workers, the self-managed Taobao shop generated a sense of ease and freedom for them. Converted from wage earners into managers, they achieved ample recognition within their new identities. A young Large Taobao trader captured this in stating that, 'Running my own business is definitely better than working for others. It has more freedom and ease; above all, you care more when it's your own business'.

Since 2013, through government praise and numerous news media reports, Junpu village has gained much of its fame nationwide. ${ }^{9}$ 'I never thought about a remote village in eastern Guangdong actually becoming China's Taobao village' (Liu, 2014). As members of the Taobao

\footnotetext{
9 Since July 2013, the news has reported extensively on Junpu Taobao villages. Related reports can be found in Nanfang Daily, Southern Metropolis Daily, Yangcheng Evening News, China Daily, People's Daily and other media with greater influences. Moreover, the story has also been reported by the Financial Channel of CCTV, Southern TV, the Pearl River channel, and Liaoning TV.
} 
village, these young people experienced an unprecedented sense of pride from this social recognition, which was a complete reversal of their diminished identities developed while working as migrant workers in cities. 'The outside people call us "the Junpu elites", and we say that it was sheer luck; we just happened to come across with it. Ha-ha' (Ordinary Taobao shop owner, female, 40s). The power represented by the 'Taobao' symbol has reconstructed the emotional belonging and identity of Junpu village as a community. Like traditional communities that had achieved redevelopment through the tourism economy, the Taobao economy has revitalized villagers' pride in their community, which signifies modernity and progress (Cui and Ryan, 2011).

Migrants returning to the countryside are seen as an outcome of the modernization of Chinese cities that had also generated clash of urbanism and rurality in the identity of the rural younger generation. With the rapid increase of living costs in urban areas, urbanism imbued a sense of modernity's rootlessness in young people, thus producing exhaustion with and alienation towards urban life. When the 'wave of returning' became 'a modernist discourse of rurality' (Bye, 2009: 279) for many Taobao villages, it altered the public perceptions of the traditional and backward rurality compared with modern and progressive urbanism. The development of Taobao in Junpu village has provided a wealth of emotional identity reconstructions for the villagers.

The reappearance of intact family units and the rekindling of family emotions, self-esteem, a sense of freedom and accomplishment in young people jointly reshaped the identity of traditional rural communities and inspired a return to rural values. Simultaneously, women's recommencement of their roles within the family also reflected the resurgence of the patriarchal system in rural families. Modern network trading released the vigour and vitality of the countryside; however, by sacrificing personal career development and resuming a subordinate role 
within the family, women consequently also participated in a return to patriarchal family structures. Through the refraction of the replicated emotional identity, rurality highlighted the intertwined and hybrid nature of social progress and the binding family role of women in Junpu village.

\section{Reconstruction of the rhythm and space of rural life}

\subsection{Time in daily Taobao practices}

The characteristics of social time derive from the common beliefs and habits of local communities, which help further reveal the unique rhythm and cadence of the location (Hassard, 1990), and a 'rhythmanalysis' (Lefebvre, 1983) becomes helpful to understand this phenomenon. Taobao practices that are embedded in the everyday life of Junpu village have contributed to the construction of the village's social-temporal rhythms.

Most villagers' perceptions of time and practices were shaped by the schedule of the logistics industry and online consumers. This means that the time mode of Junpu village shifted in order to follow the 'Taobao rhythm' of the Information Era, having previously followed the 'machine rhythm' of the industrialization era. This new time system is very different from that of the traditional countryside, which is limited by the industry processes of the local entities and the other people in the virtual network. First, transactions in cyberspace affected the villagers' time allocation for and experience of daily activities. Their businesses attracted all types of consumers, and the randomness of online shopping caused by the overwhelming consumer population meant that villagers were not able to have fixed working hours. Survey data from 2013 showed that the daily time distribution of Chinese online shoppers' browsing on an online shopping website was 
fragmented; shoppers most often browsed the website during 'leisure time at home'. ${ }^{10}$ The arbitrariness of the customers' shopping time required the villagers to conduct online customer service periodically throughout every day. The integration of e-commerce into the schedules and routines of villagers is usefully demonstrated in the example of the 'ding-dong' ringtone that is used while contacting customers. This shifted shoppers from being other people on the network to being part of the villagers' lives, and it has gradually become a symbol of the rural Taobao rhythm. As one Ordinary Taobao shop owner in her 40s explained,

At the beginning, everybody loved to hear the sound and could not wait to turn the sound louder. Ha-ha. Upon hearing the sound, the reaction is 'you have such a good business!' Now, everybody has gotten used to it and takes it as an everyday routine.

Although the e-commerce industry has satisfied villagers economically and emotionally, everyday routines have also been alienated by unregulated and disordered working hours. For the residents of Junpu village, Taobao practices have become an important component of their daily lives. In this way, 'everyday life had ceased to be a "subject" rich in potential subjectivity" (Lefebvre, 2000: 59) and has rather been transformed into an 'object' that is limited by the Taobao industrial chain. This means that operating Taobao shops has alienated their perceptions and practices of daily life. Through the interviews and non-participatory observations, it was revealed that at sunset every day, the courier service collected shipments, and the villagers hustled and bustled in the wholesale stores on 'Wisdom Avenue' to send and receive merchandise. These occupations have become the new fixtures of everyday activities in Junpu village, as sunset traditionally marked the beginning of resting hours. Logistics and online transaction practices

\footnotetext{
${ }^{10}$ China Internet Network Information Centre (2015), "2014 Report of China's Online Shopping Market Survey”, available online at: http://www.cnnic.cn/hlwfzyj/hlwxzbg/dzswbg/201509/t20150909 52821.htm, last accessed 15 September 2015.
} 
have reconstructed the social time rhythm of the countryside, and the alienated 'living' time has become routine in the Taobao villages. As one Large Taobao trader in his 20s explained,

As there is no fixed time for the buyers, sometimes two or three o'clock at night, some buyers still were asking about the goods and price. The computer has to be on all day, and you cannot turn it off. At times, when the logistics were relatively slow, two or three o'clock at night people would send you a message to urge the shipment; sometimes, even at night, you would be awakened by a buyer's call, and then it is difficult to go back to sleep. You have to cope with it.

In investigating time allocation in rural households, Vanek (1980) found that working hours, family time, and leisure time were intertwined in daily life and therefore working time was not separately allocated. In rural families that ran small-scale businesses, work time and family time intersected and were not compartmentalized (Beach, 1987). Superficially, the daily rhythm of life in Junpu village also existed in an interwoven state, but all of the family time was spent while simultaneously working and this led to the alienation of this time. This type of alienation was rather similar to the state of domestication described by Laegran (2008), in which working hours and other family time and leisure time were divided. But in Junpu village, the alienation of time more thoroughly embodied the discipline of modernity

\subsection{Time within the rural traditional daily routines}

Although modernity plays a primary role in the changes seen in the life-rhythm of Junpu villagers, a few farmers still lived in traditional rural life-rhythms. These community members either had insufficient IT knowledge or lacked interest, and they were therefore unable to live a modernised lifestyle. Their routines and lifestyles were more traditional and characteristic of the 
countryside, as they woke at sunrise and rested after sunset. For the Taobao households in which elders were still engaged in farming, the network economy introduced a very different time experience for each of the two generations. The elders who usually had meals together with family members could not bear the disrupted mealtime and work-rest schedule of the younger generation and therefore chose to cook by themselves. By not conforming to the disordered demands of the younger generation's schedule, the older generation was able to rid themselves of the alienation and attempted to humanize their lives (Heller, 1984). As one elderly Ordinary Taobao shop owner described,

My grandsons are doing Taobao and usually get up after 12:00 pm. They often have lunch at 1:00 pm or later, supper at seven or eight in the evening. They asked me to have meals with them, but I said no; it's always too late. I cook and eat by myself.

These disrupted time practices have made the Junpu village a space in which two types of daily life rhythms (the traditional farming village and the Taobao-modern village) negotiate with each other. Notably, the traditional festivals were still strongly influential in the time rhythm of Junpu village. In Chaoshan rural areas, the most solemn traditional folk activity during the Spring Festival is the carnival of the travelling god, commonly known as the 'God-Welcoming Festival' (Editorial Department of Bibles of Anecdotes, 2013). All community members participate in devout prayer activity for this festival, regardless of their other commitments or usual place of residence (Zhang, 2008).

From 8 January to 11 January on the Chinese lunar calendar, festivities are organised by the various clans on a rotational basis. During this ceremony, all villagers regardless of age and social status dress in traditional clothes and hold traditional flags, and reverently carry the shrine with the 
portrait of the god around the village in processions that are meant to welcome the god with offerings and incense. The Chaozhou music, offerings, incense and firecrackers provide splendid sounds and scents, and a joyous scene (Fig. 3). These fervent annual grassroots religious activities maintain the authority of the traditional time rhythm within the rural space.

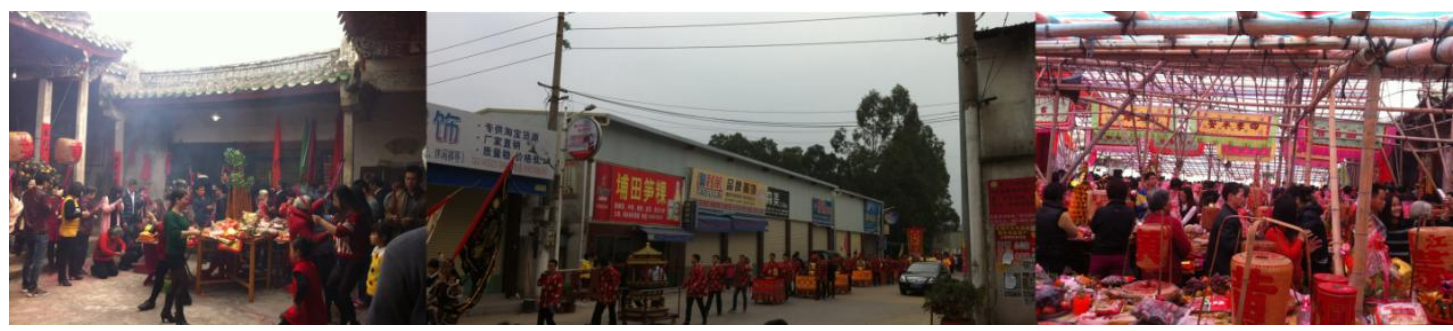

Fig. 3. The God-Welcoming Festival of Junpu village in January of the Chinese lunar calendar.

Data source: photographs by the authors.

Lefebvre (1987) argued that modernity and everyday life together constituted a deep structure in which the everyday life is constantly alienated during encounters with modern civilization. Given the strong impact of modernity, elders' roles as the leaders of the village appeared to have been gradually transferred to other people in the modern village. Taobao practices' reconstruction of the daily life rhythm of Junpu village has essentially been a process of alienation that has engulfed all Taobao households. This has occurred particularly in cases where the elderly had an intact family (as expected), but had to make concessions with their traditional rhythm of life. This type of alienation has been met with resistance in the form of farming culture, which stubbornly rejects modernisation. The localization of this process within the rural areas reflects the valuable, emotional protection of the rhythm of traditional life that is provided through the continuation of traditional farming practices. 
In constructing a rural idyll and community, traditional festivals, also have a significant role to play in the resistance of advancing modernity (Winchester and Rofe, 2005). Ekman (1999) thought that the festivals, celebrations and performances were all pursuits of tradition and continuity in a rapidly changing world, as people were able to defend local characteristics and traditions by adhering to specific rituals and cultural events. As the 'local roots' of rural communities, festivals not only act as enjoyable interruptions in the commonplace of everyday life but also represent the reconstruction and return of rurality, belonging and identity shared by local communities. The reconstruction of the rhythm of daily life in Junpu village exhibited characteristics of the high hybridity of modernity and rurality in the dimension of time.

\section{Separation of rural daily spaces}

Through the implementation of a grassroots-style Taobao economy, Junpu village became a site of local significance. In an effort to build an e-commerce port of the $21^{\text {st }}$-century Maritime Silk Road, the local government decided to adopt the Junpu village development model in order to promote the development of the city's e-commerce industry'. ${ }^{11}$ Junpu village has become a symbolic space that exemplifies the government's strategic intentions. After only a year and a half, rural architecture was replaced by various urbanized landscapes, producing a collage-style, quasi-urban space in the traditional countryside. The road leading to the village is called 'Wisdom Avenue', which the local government planned to use in order to develop a brick-and-mortar network of wholesale stores that would specifically spatially signify the local importance of Junpu village (Peet, 1999). Traditional local residences are found south of Wisdom Avenue and are

\footnotetext{
11 "To build the Maritime Silk Road e-commerce port in Jieyang, Guangdong", International Online, 12 December 2014, available online at: http://news.sina.com.cn/o/p/2014-12-12/112231277841.shtml, last accessed 10 May 2015.
} 
mainly inhabited by the elderly population. This rapid transformation has generated mixed feelings in relation to the villagers' spatial experiences. An urban-flavoured Taobao university café, ${ }^{12}$ banks of all sizes and networked shopping malls are located at the entrance to the village. These microscopic and fragmented urbanized spaces directly satisfy the villagers' urban imagination, particularly that of the younger generation. One Ordinary Taobao shop owner in his 40 s told us that,

Not far from the intersection of Wisdom Avenue, there is a large shopping mall. The designs are very interesting. There are elevators, even a large-screen TV, like in the cities. This is the countryside, but when you enter the mall, you feel like you are in the city.

Despite the positive responses to the changes to the village, this type of spatial transformation was inescapability and 'deliberately made up of bits and pieces of cultural reference' (Zukin, 2009: xii). These collage-style urbanized spaces also generated feelings of isolation and alienation for the villagers. Although many villagers enjoyed discussing this 'urbanization' in the village, a large Taobao trader in his 20s told us that the villagers also often said, 'I haven't been there yet', 'I saw it when I passed by', or 'We have never been to the café; only business people go there'.

In transforming the rural space, the concept of 'urban planning functional zoning' was introduced, which led to the separation of traditional everyday life spaces from commercial spaces. Most elderly people in the village classified the rural space into the 'upper places' and the 'lower places'. The former referred to places such as Wisdom Avenue where young people gathered, while the latter referred to traditional rural residential areas. Most elderly people rarely 12 For more details, please see Taobao Forum, available online at: http://bbs.taobao.com/catalog/thread/493528-268511551.htm?spm=5322.3059637.a214cf0.4, last accessed 10 May 2015. 
visited the 'upper places' as part of their daily activities. By feeling and experiencing space in the physical sense (Heller, 1984), the 'upper' and 'lower' zones were able to gain significance as social spaces. Sargeson (2002) believes that differentiation of rural daily life space is an effective means of allowing various family members who have different lifestyles and belong to different generations to maintain harmonious relationships with each other.

In this case, however, the space-related behaviour of the elderly in terms of their refusal to visit the 'upper places' shows that they feel 'out of place' (Cresswell, 1996). The delineation of spatial occupation by the various generations meant that the elderly identified with the traditional residential areas of the 'lower places'. Restrictions in access to the spaces where they were able to be active led them to feel 'sheer boredom' in their everyday lives. The elderly did not want to visit the 'upper places' where the village's e-commerce was concentrated, and many chose to visit the ancestral temple to play 'guessing picture' (a gambling game) instead, thereby spending time at their ancestral temple and seeking solace in this space. The elderly people attempted to find a place for retreat in confronting the division of spatial functions that had occurred during rural planning. They perceived a clear boundary between 'lower places' (the everyday space) and 'upper places' (working space that they did not feel a part of), and so in order to retain the spirit and lifestyle of the traditional rural village, they would take walks. An ordinary villager in his $40 \mathrm{~s}$ explained that,

In the side of the village with the old houses, it has always been very quiet; it's the upper places that are always lively. In the upper places, they are doing Taobao business until very late in the evening. Here, there are mainly seniors and kids; no one is doing business. They go to bed very early. 
The development of capitalism has shown that modernity could directly cause the restructuring of consumption in the rural landscape (Murdoch, 1995; Murdoch and Marsden, 1994), leading to the creative destruction of the rural idyll (Mitchell, 1998), and even the social isolation of the elderly (Shergold and Parkhurst, 2012). While Taobao has produced a novel landscape for young people to enjoy in Junpu village, it has also generated a sense of alienation for them. Moreover, Taobao has brought about a sense of spatial segregation among the elderly. The expansion of Wisdom Avenue demonstrates the power of modernity, and the shrinking residential areas reflect the persistence and desire for rurality, as well as the elderly's resistance to modernity. Taobao therefore appears at the intersection of resistance to and support for modernity, and continues to operate under a network economy, despite the will of community of members.

\section{Conclusion}

Guldin (1997), having adopted perspective of the discontinuity of traditional practices that was accepted by modernity theorists, also believes that China's rural areas will gradually vanish against the strategic background of urbanization. Chung (2013), however, finds that rurality has not been violently extinguished by urbanization, as otherwise expected. Indeed, traditional practices are intertwined with new life experiences. The relationship between modernity and rurality has gradually transformed from a binary dialogue of mutual resistance and compromise (Qian et al., 2012) to a pluralistic and hybrid perspective that is full of vitality (Murdoch, 2003; Shubin, 2006; Woods, 2007). As one of three retail giants currently leveraging the global 
economy, the nascent Alibaba has introduced drastic changes to China's rural areas through the expansion of the Internet to these locations. ${ }^{13}$

In Junpu village, Taobao practices have become a technical catalyst to the establishment of a dialogue between modernity and rurality. These advancements in scientific and technological knowledge have completely changed the social foundation of rural life for people in this area (Gottdiener, 2010). Modernity corresponds with the e-commerce economy, values and lifestyles that have surfaced in China's Information Age. This study has found that Taobao practices have reconstructed a hybrid rurality in Junpu village. The concept of hybridity echoes the notion proposed by Murdoch $(2003: 274,264)$ that the 'countryside is hybrid', and so 'rurality is also hybridity'. In this study, hybridity refers to a combination of the alienation felt from modernity and the simultaneous adherence to rurality in the Taobao villages. This rurality is shaped by network-generated control and network-inspired freedom. The alienation of rural everyday life due to online retail technology and the digestion of modernity in everyday life were synchronized, and this hybrid status appeared in various reconstruction processes, such as rural rules, rural feelings and beliefs, the pace of life, and daily space.

The erosion of rural moral self-discipline in this context and the concurrent release of subjectivity that related to the utilitarian law of the Taobao-style modern economy were coexistent and concomitant. The example of women and young people's renewed identities in the rural community was drawn on to demonstrate this process. The diminished identity and sense of belonging felt by the elderly in the community showed the complexity of the imposition of modernity experienced through the implementation of the Taobao village. We were able to

\footnotetext{
13 "2015 billboard of the most valuable Chinese brands comes out", Financial Times, 29 May 2015, available online at: http://www.alikz.com/news/6822.html, last accessed 10 September 2015.
} 
conclude that the daily rhythm of life, which was controlled by network transactions, and the complicated routine worship rituals and fervent religious festivities were able to coexist through compromise. Second, the hybrid reconstruction of rurality under the Taobao model could not occur without the tenacious power of the local culture. Junpu village endeavoured to reconstruct a rurality that seemed full of contradictions, such as women reassuming rural familial and domestic roles, alongside the form of the rurality shown in young people's experience which was modern and vibrant. Further contradictions existed in the rurality felt by the elderly people which was conservative and slow, and in this setting the rural urbanization of Taobao villages was simultaneously heralded and rejected.

From these findings, we are able to conclude that gender roles, family relations, clan, religion and other local cultural forces unique to the Chaoshan villages all contributed to this process, which wonderfully unified the alienation of modernity with the protection of tradition in the daily lives of Taobao villagers. Third, Lefebvre's theory of alienation in daily life is still able to Chinese rural areas as they operate under a network economy. However, as a hybrid of the 'old' and the 'new', rurality is ever changing and dynamic (Murdoch, 2006), and we should hold a more open theoretical position within a development perspective.

\section{Acknowledgements}

This work is sponsored by the National Science Foundation of China (Grant No: 41271164). The authors would like to thank the anonymous reviewers for their constructive comments that have helped to improve the paper. 


\section{References}

Beach, B.A., 1987. Time use in rural home-working families. Family Relations. 36 (4), 412-416.

Burholt, V., Scharf, T., Walsh, K., 2013. Imagery and imaginary of islander identity: older people and migration in Irish small-island communities. Journal of Rural Studies. 31, 1-12.

Bye, L.M., 2009. 'How to be a rural man': young men's performances and negotiations of rural masculinities. Journal of Rural Studies. 25 (3), 278-288.

Chung, H., 2013. Rural transformation and persistence of rurality in China. Eurasian Geography and Economics. 54 (5-6), 594-610.

Cloke, P., 2006. Conceptualizing rurality. In: Cloke, P., Marsden, T., Mooney, P. (Eds.), Handbook of Rural Studies. Sage, London, pp. 18-27.

Cresswell, T., 1996. In Place/Out of Place: Geography, Ideology and Transgression. University of Minnesota Press, Minneapolis.

Cui, X., Ryan, C., 2011. Perceptions of place, modernity and the impacts of tourism - differences among rural and urban residents of Ankang, China: a likelihood ratio analysis. Tourism Management. 32 (3), 604-615.

de Certeau, M., 1988. The Practice of Everyday Life. University of California Press, Berkeley.

Easthope, H., 2004. A place called home. Housing Theory and Society. 21 (3), 128-138.

Editorial Department of Bibles of Anecdotes, 2013. Guangdong Traditional Anecdotes and Legends. Tourism and Education Publishing House, Beijing (in Chinese).

Ekman, A.K., 1999. The revival of cultural celebrations in regional Sweden: aspects of tradition and transition. Socilogia Ruralis. 39 (3), 280-293.

Fang, Y., Liu, J., 2014. The modification of North China quadrangle in response to rural social and economic changes in agricultural villages: 1970-2010s. Land Use Policy. 39, 266-280.

Fei, X., 2008. From the Soil, the Foundation of Chinese Society. People's Publishing House, Beijing (in Chinese).

Gottdiener, M., 2010. The Social Production of Urban Space. University of Texas Press, Austin.

Guldin, G.E., 1997. Farewell to Peasant China: Rural Urbanization and Social Change in the Late Twentieth Century. M.E. Sharpe, New York.

Halfacree, K., 2006. Rural space: constructing a three-fold architecture. In: Cloke, P., Marsden, T., 
Mooney, P. (Eds.), Handbook of Rural Studies. Sage, London, pp. 44-62.

Halfacree, K., 2009. Rurality and post-rurality. In: Kitchin, R., Thrift, N. (Eds.), International Encyclopaedia of Human Geography. Elsevier, Amsterdam, pp. 449-456.

Hassard, J., 1990. The Sociology of Time. St. Martin's Press, New York.

Heley, J., Jones, L., 2012. Relational rurals: some thoughts on relating things and theory in rural studies. Journal of Rural Studies. 28 (3), 208-217.

Heller, A., 1984. Everyday Life. Routledge \& Kegan Paul, Boston.

Hoggart, K., Paniagua, A., 2001. What rural restructuring? Journal of Rural Studies. 17 (1), 41-62.

Hopkins, J., 1998. Signs of the post-rural: marketing myths of a symbolic countryside. Geografiska Annaler. 80 (2), 65-81.

Huhe, N., Chen, J., Tang, M., 2015. Social trust and grassroots governance in rural China. Social Science Research. 53, 351-363.

Jackson, P., 1991. Mapping meanings: a cultural critique of locality studies. Environment and Planning A. 23 (2), 215-228.

Judd, E.R., 2009. Starting again in rural west China: stories of rural women across generations. Gender \& Development. 17 (3), 441-451.

Kilpeläinen, A., Seppänen, M., 2014. Information technology and everyday life in ageing rural villages. Journal of Rural Studies. 33, 1-8.

Laegran, A.S., 2008. Domesticating home anchored work: negotiating flexibility when bringing ICT based work home in rural communities. Geoforum. 39 (6), 1991-1999.

Lee, E.S., 1966. A theory of migration. Demography. 3 (1), 47-57.

Lefebvre, H., 1983. Philosophers of everyday life study: answers of Lefebvre to the questions of World News journalists, translated by X Jiang. Social Science Trends Abroad. 9, 52-54. (in Chinese).

Lefebvre, H., 1987. The everyday and everydayness. Yale French Studies. 73, 11.

Lefebvre, H., 2000. Everyday Life in the Modern World. A \& C Black, London, pp. 59.

Lefebvre, H., 2008. Critique of Everyday Life. Verso, New York.

Ling, R.S.J., Wu, B., Park, J., Hua, S., 2013. Women's role in sustaining villages and rural tourism in China. Annals of Tourism Research. 43, 634-638. 
Liu, J., 2014. The growth of Junpu as an e-commerce village of Jieyang. XiaoKang. 11, 98-100 (in Chinese).

Liu, Z., Liu, L., 2016. Characteristics and driving factors of rural livelihood transition in the east coastal region of China: a case study of suburban Shanghai. Journal of Rural Studies. 43, $145-158$.

Long, H., Liu, Y., 2015. A brief background to rural restructuring in China: a forthcoming special issue of Journal of Rural Studies. Journal of Geographical Sciences. 25 (10), 1279-1280.

Long, H., Tu, S., Ge, D., Li, T., Liu, Y., 2016. The allocation and management of critical resources in rural China, Journal of Rural Studies, publish online at: http://dx.doi.org/10.106/j.jrurstud.2016.03.011

Long, H., Woods, M., 2011. Rural restructuring under globalization in eastern coastal China: what can be learned from Wales? Journal of Rural and Community Development. 6 (1), 70-94.

Marsden, T., 1998. New rural territories: regulating the differentiated rural spaces. Journal of Rural Studies. 14 (1), 107-119.

Marsden, T., Murdoch, J., Lowe, P., Munton, R., Flynn, A., 1993. Constructing the Countryside. UCL Press, London.

Michailidis, A., Partalidou, M., Nastis, S.A., Papadaki-Klavdianou, A., Charatsari, C., 2011. Who goes online? Evidence of Internet use patterns from rural Greece. Telecommunications Policy. 35 (4), 333-343.

Mitchell, C.J., 1998. Entrepreneurialism, commodification and creative destruction: a model of post-modern community development. Journal of Rural Studies. 14 (3), 273-286.

Murdoch, J., 1995. Middle-class territory? Some remarks on the use of class analysis in rural studies. Environment and Planning A. 27 (8), 1213-1230.

Murdoch, J., 2003. Co-constructing the countryside: hybrid networks and the extensive self. In: Cloke, P. (Ed.), Country Visions. Pearson Education, Harlow, pp. 263-282.

Murdoch, J., 2006. Networking rurality: emergent complexity in the countryside. In: Cloke, P., Marsden, T., Mooney, P. (Eds.), Handbook of Rural Studies. Sage, London, pp. 171-184.

Murdoch, J., Marsden, T., 1994. Reconstituting Rurality: Class, Community and Power in the Development Process. UCL Press, London. 
Murdoch, J., Pratt, A., 1993. Rural studies: modernism, post-modernism and the 'post-rural'. Journal of Rural Studies. 9 (4), 411-427.

Nelson, P.B., 2001. Rural restructuring in the American West: land use, family and class discourses. Journal of Rural Studies. 17 (4), 395-407.

Ooi, N., Laing, J., Mair, J., 2015. Sociocultural change facing ranchers in the Rocky Mountain West as a result of mountain resort tourism and amenity migration. Journal of Rural Studies. $41,59-71$.

Oreglia, E., 2014. ICT and (personal) development in rural China. Information Technologies \& International Development. 10 (3), 19-30.

Peet, R., 1999. Modern Geographical Thought. Blackwell Publishers, Oxford, pp. xxi.

Qian, J., Qian, L., Zhu, H., 2012. Subjectivity, modernity, and the politics of difference in a periurban village in China: towards a progressive sense of place? Environment and Planning D: Society and Space. 30 (6), 1064-1082.

Qiang, Z., Bhavnani, A., Hanna N.K., Kimura, K., Sudan, R., 2009. Rural informatization in China. World Bank Publications. 172, 1-59.

Roche, M., 2003. Rural geography: a stock tally of 2002. Progress in Human Geography. 27 (6), 779-786.

Salemink, K., Strijker, D., Bosworth, G., 2015. Rural development in the digital age: a systematic literature review on unequal availability, adoption, and use in rural areas, Journal of Rural Studies, publish online at: http://dx.doi.org/10.1016/j.jrurstud.2015.09.001

Sargeson, S., 2002. Subduing "the rural house-building craze": attitudes towards housing construction and land use controls in four Zhejiang villages. China Quarterly. 172, 927-955.

Shergold, I., Parkhurst, G., 2012. Transport-related social exclusion amongst older people in rural Southwest England and Wales. Journal of Rural Studies. 28 (4), 412-421.

Shubin, S., 2006. The changing nature of rurality and rural studies in Russia. Journal of Rural Studies. 22 (4), 422-440.

Simmel, G., 1978. The Philosophy of Money. Routledge \& Kegan Paul, Boston.

Soriano, C.R.R., 2007. Exploring the ICT and rural poverty reduction link: community telecenters and rural livelihoods in Wu'an, China. Ejisdc the Electronic Journal of Information Systems 
in Developing Countries. 32 (1), 1-15.

Vanek, J., 1980. Work, leisure, and family roles: farm households in the United States, 1920-1955. Journal of Family History. 5 (4), 422-431.

Wen, Z., An, Y., Liu, J., 2009. Community involvement in rural tourism development: evidence from Pinggu, Yanqing and Miyun Districts, Beijing Municipality. In: Ryan, C., Gu, H. (Eds.), Tourism in China: Destination, Cultures and Communities. Routledge, London, pp. 268-283.

Winchester, H.P., Rofe, M.W., 2005. Christmas in the 'Valley of Praise': intersections of the rural idyll, heritage and community in Lobethal, South Australia. Journal of Rural Studies. 21 (3), 265-279.

Woods, M., 2007. Engaging the global countryside: globalization, hybridity and the reconstitution of rural place. Progress in Human Geography. 31 (4), 485-507.

Woods, M., 2009. Rural geography: blurring boundaries and making connections. Progress in Human Geography. 33 (6), 849-858.

Woods, M., 2011. Rural. Routledge, Abingdon.

Xu, W., Tan, K.C., 2002. Impact of reform and economic restructuring on rural systems in China: a case study of Yuhang, Zhejiang. Journal of Rural Studies. 18 (1), 65-81.

Zhang, P., 2008. The Demon and the Prophet. SDX Joint Publishing Company, Beijing (in Chinese).

Zhao, J., 2008. Internet adoption and usage among rural users in China. Knowledge Technology \& Policy. 21 (1), 9-18.

Zukin, S., 2009. Naked City: The Death and Life of Authentic Urban Places. Oxford University Press, Oxford, pp. xii. 


\section{Table 1}

Basic characteristics of the 28 interviewees in Junpu village.

\begin{tabular}{|c|c|c|c|c|}
\hline ID & Sex & Age & $\begin{array}{c}\text { Do you or your family } \\
\text { members run the Taobao } \\
\text { shop? }\end{array}$ & $\begin{array}{c}\text { Size of the } \\
\text { Taobao shop }\end{array}$ \\
\hline 1 & $M$ & $35-39$ & $\mathrm{~N}$ & --- \\
\hline 2 & M & $55-59$ & $\mathrm{Y}$ & Ordinary \\
\hline 3 & M & $40-44$ & Y & Ordinary \\
\hline 4 & $\mathrm{~F}$ & $35-39$ & $\mathrm{Y}$ & Ordinary \\
\hline 5 & M & $60-64$ & $\mathrm{~N}$ & --- \\
\hline 6 & $\mathrm{~F}$ & $60-64$ & $\mathrm{Y}$ & Large \\
\hline 7 & M & $55-59$ & $\mathrm{~N}$ & --- \\
\hline 8 & M & $20-24$ & $\mathrm{Y}$ & Ordinary \\
\hline 9 & $\mathrm{~F}$ & $20-24$ & Y & Ordinary \\
\hline 10 & $\mathrm{~F}$ & $50-54$ & $\mathrm{Y}$ & Large \\
\hline 11 & F & $40-44$ & $\mathrm{Y}$ & Ordinary \\
\hline 12 & F & $20-24$ & $\mathrm{Y}$ & Ordinary \\
\hline 13 & M & $25-29$ & $\mathrm{Y}$ & Large \\
\hline 14 & M & $50-54$ & $\mathrm{Y}$ & Ordinary \\
\hline 15 & M & $25-29$ & $\mathrm{Y}$ & Ordinary \\
\hline 16 & M & $20-24$ & $\mathrm{Y}$ & Large \\
\hline 17 & M & $25-29$ & Y & Ordinary \\
\hline 18 & M & $40-44$ & $\mathrm{Y}$ & Ordinary \\
\hline 19 & M & $70-74$ & $\mathrm{Y}$ & Large \\
\hline 20 & $\mathrm{~F}$ & $20-24$ & $\mathrm{~N}$ & --- \\
\hline 21 & F & $60-64$ & $\mathrm{~N}$ & --- \\
\hline 22 & M & $70-74$ & Y & Large \\
\hline 23 & M & $45-49$ & $\mathrm{~N}$ & --- \\
\hline 24 & M & $50-54$ & $\mathrm{Y}$ & Ordinary \\
\hline 25 & M & $50-54$ & $\mathrm{Y}$ & Ordinary \\
\hline 26 & M & $40-44$ & $\mathrm{Y}$ & Ordinary \\
\hline 27 & $\mathrm{~F}$ & $45-49$ & Y & Ordinary \\
\hline 28 & $\mathrm{~F}$ & $40-44$ & Y & Ordinary \\
\hline
\end{tabular}

